This item was submitted to Loughborough's Research Repository by the author.

Items in Figshare are protected by copyright, with all rights reserved, unless otherwise indicated.

\title{
Spreading behaviour of aqueous trisiloxane solutions over hydrophobic polymer substrates
}

PLEASE CITE THE PUBLISHED VERSION

PUBLISHER

(c) Pleiades Publishing (distributed by Springer Science+Business Media LLC.)

VERSION

AM (Accepted Manuscript)

LICENCE

CC BY-NC-ND 4.0

\section{REPOSITORY RECORD}

Ping, Caleb Chong Wei, Natalia A. Ivanova, Victor Starov, Nidal Hilal, and Daniel Johnson. 2009. "Spreading Behaviour of Aqueous Trisiloxane Solutions over Hydrophobic Polymer Substrates". figshare. https://hdl.handle.net/2134/4912. 
This item was submitted to Loughborough's Institutional Repository (https://dspace.lboro.ac.uk/) by the author and is made available under the following Creative Commons Licence conditions.

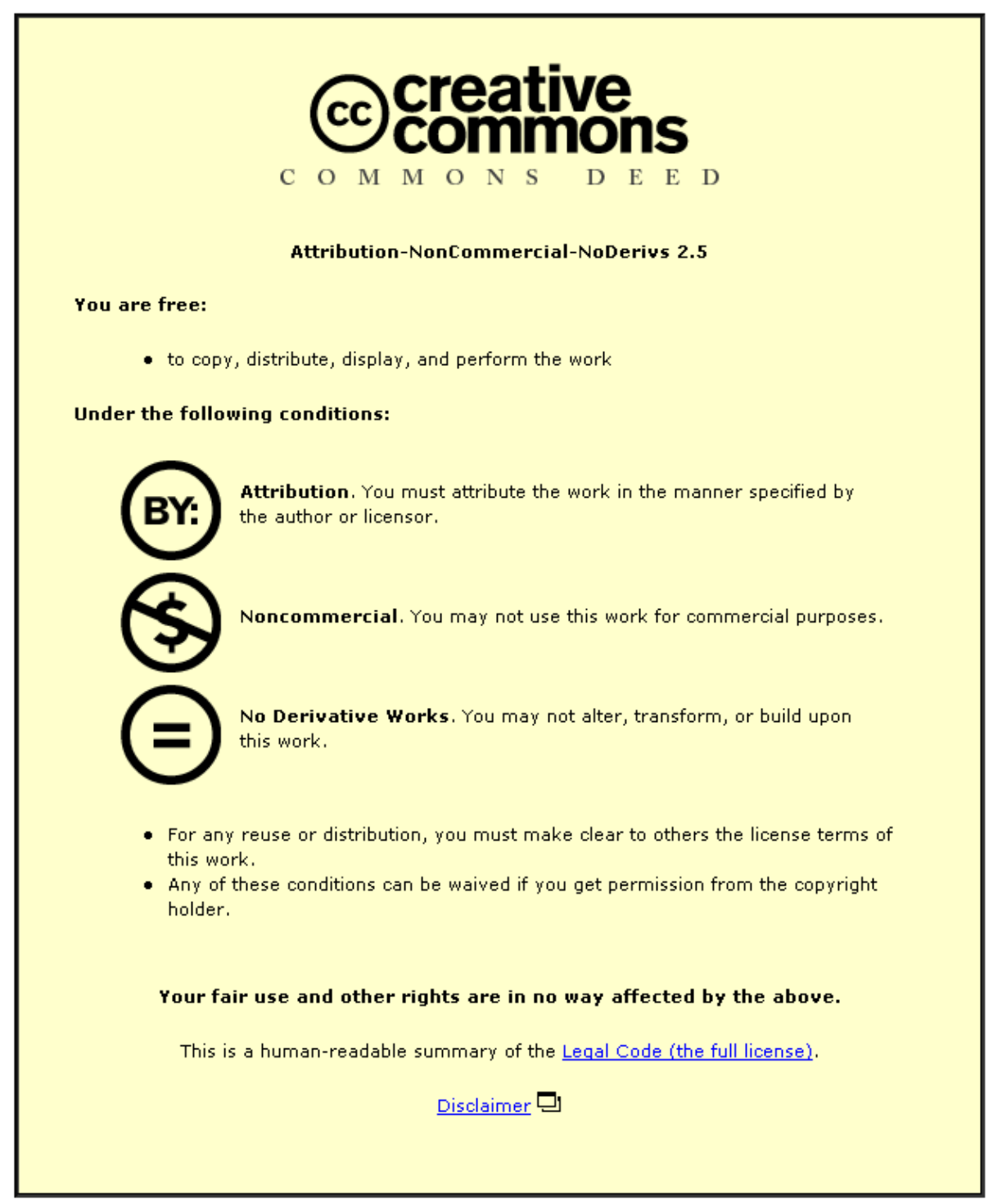

For the full text of this licence, please go to: http://creativecommons.org/licenses/by-nc-nd/2.5/ 


\title{
Spreading behaviour of aqueous trisiloxane solutions over
}

\author{
hydrophobic polymer substrates \\ Caleb Chong Wei Ping ${ }^{1}$ N. A. Ivanova ${ }^{1}$ V. M. Starov ${ }^{\mathrm{fl}}$ \\ $\mathrm{N} \mathrm{Hilal}^{2}$, D Johnson ${ }^{2}$ \\ ${ }^{1}$ Department of Chemical Engineering, Loughborough University, LE11 3TU, UK \\ e-mail: V.M.Starov@lboro.ac.uk \\ ${ }^{2}$ School of Chemical, Environmental and Mining Engineering, University of \\ Nottingham, UK
}

\begin{abstract}
The kinetics of spreading of aqueous trisiloxane solutions over different solid hydrophobic substrates has been investigated experimentally. Two pure trisiloxane surfactants with 6 and 8 polyoxyethylene groups at concentrations closed to the critical aggregation concentration (CAC) and the critical wetting concentration $(\mathrm{CWC})$ were used in the spreading experiments. The following three hydrophobic substrates (Teflon AF, Parafilm, and Polystyrene) having different surface properties were used. It was found that the spreading behaviour depends on the hydrophobic/roughness properties of substrates. The rapid spreading and complete wetting were observed for both trisiloxane surfactant solutions at the CWC on a substrate with a moderate hydrophobicity. For both highly hydrophobic Teflon AF and Parafilm substrates only partial wetting was found. The experiments have shown that the spreading behaviour over all

\footnotetext{
${ }^{\mathrm{f}}$ To whom correspondence should be addressed
} 
substrates proceeds at two stages. At the CAC for both trisiloxanes on all substrates the time lag of the spreading was detected.

\section{INTRODUCTION}

Trisiloxane surfactants consist of non-polar trisiloxane headgroups and the polar group, which is a polyethylene oxide chain. The latter is attached to the centre silicon atom of the group. Trisiloxanes are commonly denoted as $\mathrm{M}\left(\mathrm{D}^{\prime} \mathrm{E}_{n}\right) \mathrm{M}$, where $\mathrm{M}$ stands for the trimethylsiloxy group $\left(\mathrm{CH}_{3}\right)_{3} \mathrm{SiO}_{1 / 2}-$, the term $\mathrm{D}^{\prime}$ stands for the $-\mathrm{O}_{1 / 2} \mathrm{Si}\left(\mathrm{CH}_{3}\right)(\mathrm{R}) \mathrm{O}_{1 / 2}$, where $\mathrm{R}$ is a polyoxyethylene group attached to the silicon, and $\mathrm{E}_{\mathrm{n}}$ stands for polyoxyethylene - $\left(\mathrm{CH}_{2-}\right.$ $\left.\mathrm{CH}_{2} \mathrm{O}\right)_{\mathrm{n}} \mathrm{H}-$ [1]. For simplicity, trisiloxane with $\mathrm{n}$ polyoxyethylene group is referred to below as $T_{n}$. The special feature of trisiloxane surfactants is to promote spreading of aqueous solutions over hydrophobic substrates that has substantial importance in many technological applications such as coatings, paintings, agrochemicals [2].

Despite of intensive investigations of spreading of trisiloxane solutions undertaken during the past decade, the information on influence of the surface energy and chemistry of substrates on spreading behaviour is still limited.

Spreading of aqueous trisiloxane $\left(T_{6}\right.$ and $\left.T_{8}\right)$ solutions on a rough graphite substrate was reported in [3]. At the CWC the transition from the partial wetting to the complete wetting was found. Three regimes of the spreading dynamics 
were observed: (i) early stages where wetting diameter is proportional to $t^{n}$ with $n$ is in the range $0.12-0.22$; (i) during the second stage the exponent increased up to 0.58 ; (iii) during the last stage of the spreading the surface roughness and local tension gradients lead to an asymmetric drop shape and formation of fingers and dendrites.

It was shown in [4] that the spreading rate of $\mathrm{T}_{8}$ aqueous solution at concentrations above the CWC reached the maximum on a hydrophobized rough gold-coated quartz crystal substrate, where a pure water contact angle is $\cos \theta=0.4$. On substrates with higher degree of hydrophobicity $(\cos \theta=0)$ or with lower degree of hydrophobicity $(\cos \theta=1)$ the spreading rate was substantially lower as compared with above mentioned case of intermediate hydrophobicity. The reduction in the spreading rate of aqueous trisiloxane solutions at concentration above the CWC on extremely low or high surface energy of substrates was also reported in [5]. The maximum spreading rate was found on substrates characterized by water contact angles $90^{\circ}$ and $79^{\circ}$. It was also found that on highly hydrophobic surfaces rapid spreading is observed for $1 \mathrm{wt} \%$ solutions of the relatively short-chained polyoxyethylene $\left(\mathrm{T}_{5}\right.$ and $\left.\mathrm{T}_{6}\right)$ derivatives. On slightly polar surfaces dilute $0.1 \mathrm{wt} \%$ solutions of longer-chained $\left(T_{8}\right)$ derivatives spread faster. However, the results were obtained at trisiloxane concentrations much higher than both the CAC and the CWC. 
This work aims to investigate the spreading behaviour of droplets of aqueous trisiloxane surfactants solutions at concentrations $1 \mathrm{CAC}$ and $1 \mathrm{CWC}$ over different solid hydrophobic surfaces. 


\section{EXPERIMENTAL}

Non-ionic

trisiloxane

surfactants

$\left[\left(\mathrm{CH}_{3}\right)_{3} \mathrm{SiO}\right]_{2} \mathrm{Si}\left(\mathrm{CH}_{3}\right)\left(\mathrm{CH}_{2}\right)_{3}\left(\mathrm{OCH}_{2} \mathrm{CH}_{2}\right)_{\mathrm{n}} \mathrm{OH}$, denoted as $\mathrm{T}_{\mathrm{n}}$, with $\mathrm{n}=6$ and 8 ethoxy groups were provided by Dow Corning Corporation and used without further purification. Poly[4,5-difluoro-2,2-bis(trifluoromethyl)-1,3-dioxole-cotetrafluoroethylene] denoted as Teflon AF, Polystyrene standard with molecular weight $10^{5}$, and Parafilm ${ }^{\circledR}$ " $\mathrm{M}$ " (for short Parafilm) were purchased from Sigma-Aldrich, UK.

Teflon AF (0.5g) was dissolved in $200 \mathrm{ml}$ of Fluorinert F75 solvent, and Polystyrene (1g) was dissolved in $100 \mathrm{ml}$ of dichloromethane solvent. Hydrophobic polymer substrates were formed by coating silicon wafer pieces with polymer Teflon AF and/or Polystyrene solutions. The silicon wafer pieces measuring around $1 \times 1 \mathrm{~cm}^{2}$ were carefully cleaned according to the following protocol: $30 \mathrm{~min}$ ultrasonication in isopropyl alcohol, then rinsing in distilled water and soaked in chromic acid for 1 hour, intensive rinse in distilled water and DI water, and then dried in a strong air jet. Then silicone wafer pieces were placed in a covered dish and polymer solution was deposited on each piece. After this procedure the silicone wafer pieces were left for 24 hours in order to evaporate the solvent. 
Parafilm substrates were prepared in the following way. Parafilm pieces measuring around $1 \times 1 \mathrm{~cm}^{2}$ were cut and attached with a small pure water droplet to the silicon wafers pre-cleaned according to the above procedure.

Surface topology of polymer coated silicon wafers was inspected using Atomic Force Microscopy. The thicknesses of Teflon AF and Polystyrene films on wafers were measured by using SG-Certus film thickness measurement system (Scalar Technologies, UK). The data of the macroscopic contact angle of water thickness of films and roughness for polymer substrates are summarized in Table 1. The latter Table shows that the surface of silicone wafer pieces covered by Teflon AF was found substantially smoother and more hydrophobic as compared with the other polymer surfaces.

Aqueous solutions of surfactants were prepared with ultra pure water obtained from a Millipore filter $(18.2 \mathrm{M} \Omega \mathrm{cm})$. The concentrations of solutions under investigation were around the critical aggregate concentration (CAC) at which trisiloxanes form aggregates/vesicles $[1,6]$, and the critical wetting concentration (CWC) [6]. The $\mathrm{CAC}, \mathrm{CWC}$ and surface tension values at $\mathrm{CAC}$ for $T_{6}$ and $T_{8}$ trisiloxanes are presented in Table 2.

All experiments were conducted in a closed chamber at $22 \pm 1^{\circ} \mathrm{C}$ and $60 \pm 5 \%$ humidity. A droplet of the surfactant solution of $2.6 \pm 0.3 \mu \mathrm{L}$ was deposited on a polymer coated wafer with a precision syringe. The smallness of the droplet size allowed neglecting the gravity action. 
The side view of the spreading process was captured using a CCD camera at a rate of 30 fps. Slowly spreading droplets were observed for at least 100s, and fast spreading droplets over $5 \mathrm{~s}$. Captured images then were automatically analysed by using Drop tracking and evaluation analysis software developed by Micropore Technologies, UK for monitoring the time evolution of the diameter, height, radius of curvature and contact angle of spreading droplets. The experiments were repeated at least four times to control the reproducibility for each solution. Contact angles were averaged with an accuracy $1^{\circ}-3^{\circ}$. The change of droplet volume caused by evaporation was found less than $5 \%$.

\section{RESULTS AND DISCUSSION}

Figs. $1-3$ summarize the time evolution of a diameter of droplets base of $\mathrm{T}_{6}$ and $\mathrm{T}_{8}$ trisiloxane solutions at concentrations the CAC and the CWC spread over polymer hydrophobic substrates. It was found that the spreading process proceeds in two stages over all Polystyrene, Parafilm and Teflon AF substrates. In case of concentrations closed to the CAC the droplets of both trisiloxanes start spreading in about $0.3 \mathrm{~s}$ after the deposition of droplets on any polymer substrates investigated (see Figs. $1-3$ ). Note, in experiments on spreading over Teflon AF concentration of $\mathrm{T}_{8}$ solution was about 1.5 CAC, hence, the time lag in this case was slightly shorter than for 1 CAC solutions (Fig. 3).

At concentration $C \approx \mathrm{CAC}$ the droplets of both $\mathrm{T}_{6}$ and $\mathrm{T}_{8}$ solutions spread at the first stage for $18-20 \mathrm{~s}$ over all substrates. After that over both Parafilm 
and Teflon AF substrates the spreading process proceeded rather slower: the second stage started, which was lasted up to 100 s (Figs. 2 - 3). In the case of Polystyrene surface the spreading rate at the second stage was drastically increased (see Fig. 1).

At high concentration $(\sim 1 \mathrm{CWC})$ the droplets of both trisiloxane solutions start spreading over all investigated polymer substrates immediately after the deposition. In this case the spreading was rather fast and the total process of spreading was completed in $5 \mathrm{~s}$ on Polystyrene substrate, and in about $25 \mathrm{~s}$ on Teflon AF and Parafilm substrates. For the droplets of $\mathrm{T}_{6}$ solution on Parafilm and Polystyrene substrates the first stage took less than $0.5 \mathrm{~s}$, and then the spreading develops during the second faster stage. For $\mathrm{T}_{8}$ solution the first stage was shorter than for $\mathrm{T}_{6}$ solution. In the case of smooth and highly hydrophobic Teflon AF substrates (see Fig. 3) the first stage took few seconds, and the time evolution of the diameter of droplet base was much slower as compared with Polystyrene and Parafilm substrates.

The dependencies of the diameter droplet base on the spreading time, $D(t)$, were fitted using a power law $D_{i}(t)=A_{i} t^{n_{i}}$ for each stage (Fig. 4), where $D(t)$ is the diameter of the droplet base, $n$ is the fitted exponent, and $A$ is the prefactor, $i-$ is the subscript that corresponds to the first or the second stages. The values of fitting exponent for all experimental data are presented in Table 3. 
Table 3 shows that the values of exponents $n_{1}$ corresponding to the first stage for both trisiloxanes, both concentrations and for all substrates used are quite similar and rang between 0.3 and 0.6 for Teflon/Parafilm and Polystyrene, correspondingly. However, the values of exponents $n_{2}$ at the second stage are vary substantially and depend on the properties of the substrates. The lowest values of $n_{2}$ corresponds to highly hydrophobic and rather smooth Teflon AF substrates (see Table 1). The highest $n_{2}$ values fit the spreading curves for low hydrophobic and more rough Polystyrene substrates (see Table 1). Moreover, for Teflon $\mathrm{AF}$ (cases of $C=\mathrm{CAC}$ and $C=\mathrm{CWC})$ and Parafilm $(C=\mathrm{CAC})$ the values of $n_{2}$ for both trisiloxane solutions are less than the values of $n_{1}\left(n_{2}<\right.$ $n_{1}$ ). The latter means, that in those both cases the spreading is mostly completed during the first stage where $n_{1}=0.3-0.6$ that corresponds to a partial wetting.

Indeed, Fig. 5 shows the time dependencies of the cosine of contact angle for the CAC solutions spreading over hydrophobic surfaces, the droplets of both $\mathrm{T}_{6}$ and $\mathrm{T}_{8}$ solutions did not wet completely the Teflon AF and Parafilm surfaces, they wet only partially those polymer surfaces. The final contact angles reached by droplets of trisiloxane solutions were found in the range $70^{\circ}-60^{\circ}$ on Teflon AF and Parafilm (see Fig. 5). In the case of the low hydrophobic and quite rough Polystyrene substrates, where $n_{2}>n_{1}$, the both trisiloxane solutions at $C=\mathrm{CAC}$ showed a complete wetting behaviour (Fig. 5). However, the 
spreading process is rather slow, e.g. according to our observations of $T_{8}$ solution the contact angle went down to $20^{\circ}$ in more than $100 \mathrm{~s}$.

Table 3 shows that at concentrations the CWC the exponents $n_{2}$ for $\mathrm{T}_{6}$ and $\mathrm{T}_{8}$ solutions on Polystyrene and Parafilm substrates are ranging from 0.08 to 0.16 that it close to Tanner's law of spreading $(n=0.1)$ [7]. The latter means that in this case there is capillary regime of the spreading, which corresponds to the complete wetting case. In Fig. 6 the cosine of contact angle on the spreading time is presented for the CWC trisiloxane solutions spreading over different polymer substrates. The droplets of both $\mathrm{T}_{6}$ and $\mathrm{T}_{8}$ solutions completely wet the Parafilm and Polystyrene substrates, and only on Teflon AF substrate the partial wetting behaviour of the droplets was observed. Note, in Fig. 6 the values of final contact angles of droplets on Polystyrene and Parafilm are presented at the moments when the contact angle was still measurable.

It was also found (Fig. 5 and Fig. 6) that the values of initial contact angle of droplets of both trisiloxane solutions depend on the hydrophobicity of substrates. On the Teflon AF surface the initial contact angle took values close to $90^{\circ}$ and its values decreased down to $60^{\circ}-50^{\circ}$ for low hydrophobic Parafilm and Polystyrene substrates. 


\section{Conclusions}

The kinetic of spreading of aqueous $\mathrm{T}_{6}$ and $\mathrm{T}_{8}$ trisiloxane surfactant solutions over different solid hydrophobic substrates were experimentally studied. Three hydrophobic substrates Teflon AF, Parafilm, and Polystyrene were used in the experiments. It was found that the spreading behaviour over all substrates proceeds at two stages. For both trisiloxanes used at the CAC concentration on all substrates the short time lag of the spreading was detected.

The spreading behaviour depends on the hydrophobic/roughness properties of substrates. In the case of spreading over low hydrophobic Polystyrene substrate the complete wetting was found for both $T_{6}$ and $T_{8}$ trisiloxane solutions at both the CAC and the CWC concentrations. On highly hydrophobic Teflon AF substrates only partial wetting took place.

\section{Acknowledgement}

The researches were supported by Engineering and Physical Sciences Research Council, UK. 


\section{References}

1. Hill R.M., He M., Davis H.T., Scriven L.E., Langmuir, 1994, vol. 10, p. 1724.

2. Silicone Surfactants; Hill, R. M., Ed.; Surfactant Science Series, Vol. 86; Marcel Dekker: New York, 1999.

3. Svitova T., Hill M.R., Radke C.J., Colloid and Surfaces A: Physchem. and Eng. Aspects, 2001, vol. 183-185, p. 601.

4. Stoebe T., Lin Z. Hill R.M., Ward M. D., Davis H.T. Langmuir, 1996, vol. 12, p. 337.

5. Wagner R., Wu Y., v. Berlepsch H., Perepelittchenko L. Appl. Organometal. Chem., 2000, vol. 14, p. 177.

6. Svitova T., Hill R.M., Smirnova Yu., Stuermer A., Yakubov G. Langmuir, 1998, vol. 14, p. 5023.

7. Leger L., Joanny J.F. Rep. Prog. Phys., 1992, p. 431. 
Table 1. Macroscopic contact angle of water, film thickness, and roughness factor of polymeric substrates.

\begin{tabular}{lccc}
\hline $\begin{array}{l}\text { Polymeric } \\
\text { substrates }\end{array}$ & $\begin{array}{c}\text { Water contact } \\
\text { angle, }\left({ }^{\circ}\right)\end{array}$ & $\begin{array}{c}\text { Thickness of } \\
\text { polymer film } \\
(\mu \mathrm{m})\end{array}$ & $\begin{array}{c}\text { RMS roughness } \\
\left(50 \times 50 \mu \mathrm{m}^{2}\right)\end{array}$ \\
\hline Teflon AF & $117 \pm 1$ & $0.86 \pm 0.03$ & $<5$ \\
Polystyrene & $85 \pm 3$ & $1.9 \pm 0.2$ & $>30$ \\
Parafilm & $106 \pm 2$ & - & $\sim 60$ \\
\hline
\end{tabular}


Table 2. Values of the CAC, CWC and surfaces tension at the CAC for trisiloxanes.

\begin{tabular}{lrccc}
\hline Surfactant & $\mathrm{CAC}, \mathrm{mol} / \mathrm{L}$ & $\mathrm{CWC}, \mathrm{mol} / \mathrm{L}$ & $\begin{array}{c}\gamma, \mathrm{mN} / \mathrm{m} \\
\text { at CAC }\end{array}$ & $\begin{array}{c}\text { Molecular } \\
\text { weight }\end{array}$ \\
\hline $\mathrm{T}_{6}[6]$ & $9.6 \times 10^{-5}$ & $5.52 \times 10^{-4}$ & - & $544^{*}$ \\
$\mathrm{~T}_{8}[6]$ & $10.9 \times 10^{-5}$ & $7.9 \times 10^{-4}$ & 22 & $632^{*}$ \\
\hline
\end{tabular}

* - molecular weight calculated using equation from [1] 
Table 3. Values of the fitted exponent $n$ for trisiloxane solutions at different concentrations on different polymer substrates

\begin{tabular}{cccccc}
\hline Substrate & Concentration & $\begin{array}{c}\boldsymbol{n}_{\mathbf{1}} \\
\mathbf{1}^{\text {st }} \text { stage }\end{array}$ & $\begin{array}{c}\mathbf{T}_{\mathbf{6}} \\
\mathbf{2}^{\text {nd }} \text { stage }\end{array}$ & $\begin{array}{c}\boldsymbol{n}_{\mathbf{1}} \\
\mathbf{1}^{\text {st }} \text { stage }\end{array}$ & $\begin{array}{c}\mathbf{T}_{\mathbf{8}} \\
\mathbf{2}^{\text {nd }} \mathbf{s t a g e ~}^{\mathbf{n}}\end{array}$ \\
\hline $\begin{array}{cccccc}\text { Polystyrene } \\
\theta_{\mathrm{w}}=85^{\circ}\end{array}$ & CAC & 0.051 & 0.093 & 0.041 & 0.070 \\
Parafilm & CWC & 0.060 & 0.160 & 0.034 & 0.100 \\
$\theta_{\mathrm{w}}=106^{\circ}$ & CAC & 0.032 & 0.012 & 0.037 & 0.021 \\
Teflon AF & CWC & 0.044 & 0.122 & 0.046 & 0.082 \\
$\theta_{\mathrm{w}}=117^{\circ}$ & CAC & 0.032 & 0.017 & 0.033 & 0.017 \\
& CWC & 0.047 & 0.007 & 0.026 & 0.009 \\
\hline
\end{tabular}




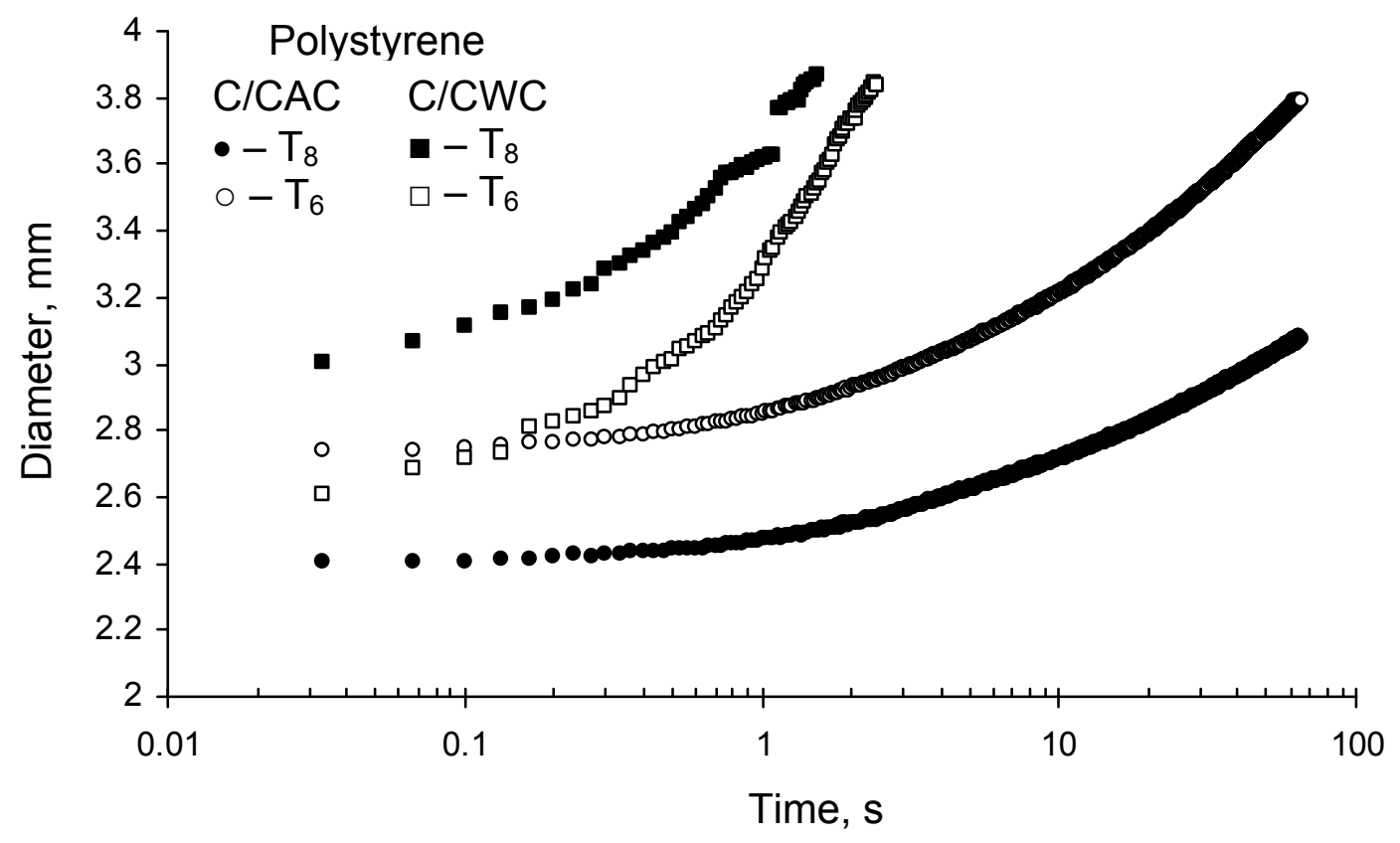

Fig. 1. Spreading kinetic of the droplets of $\mathrm{T}_{6}$ and $\mathrm{T}_{8}$ solutions at concentration $1 \mathrm{CAC}$ and $1 \mathrm{CWC}$ over Polystyrene substrate. Concentrations/trisiloxanes: $\bullet-\mathrm{T}_{8}$ solution/1 CAC; $\mathrm{O}-$ $\mathrm{T}_{6}$ solution/1 CAC; - $\mathrm{T}_{8}$ solution/ $1 \mathrm{CWC} ; \square-\mathrm{T}_{6}$ solution/1 $\mathrm{CWC}$. 


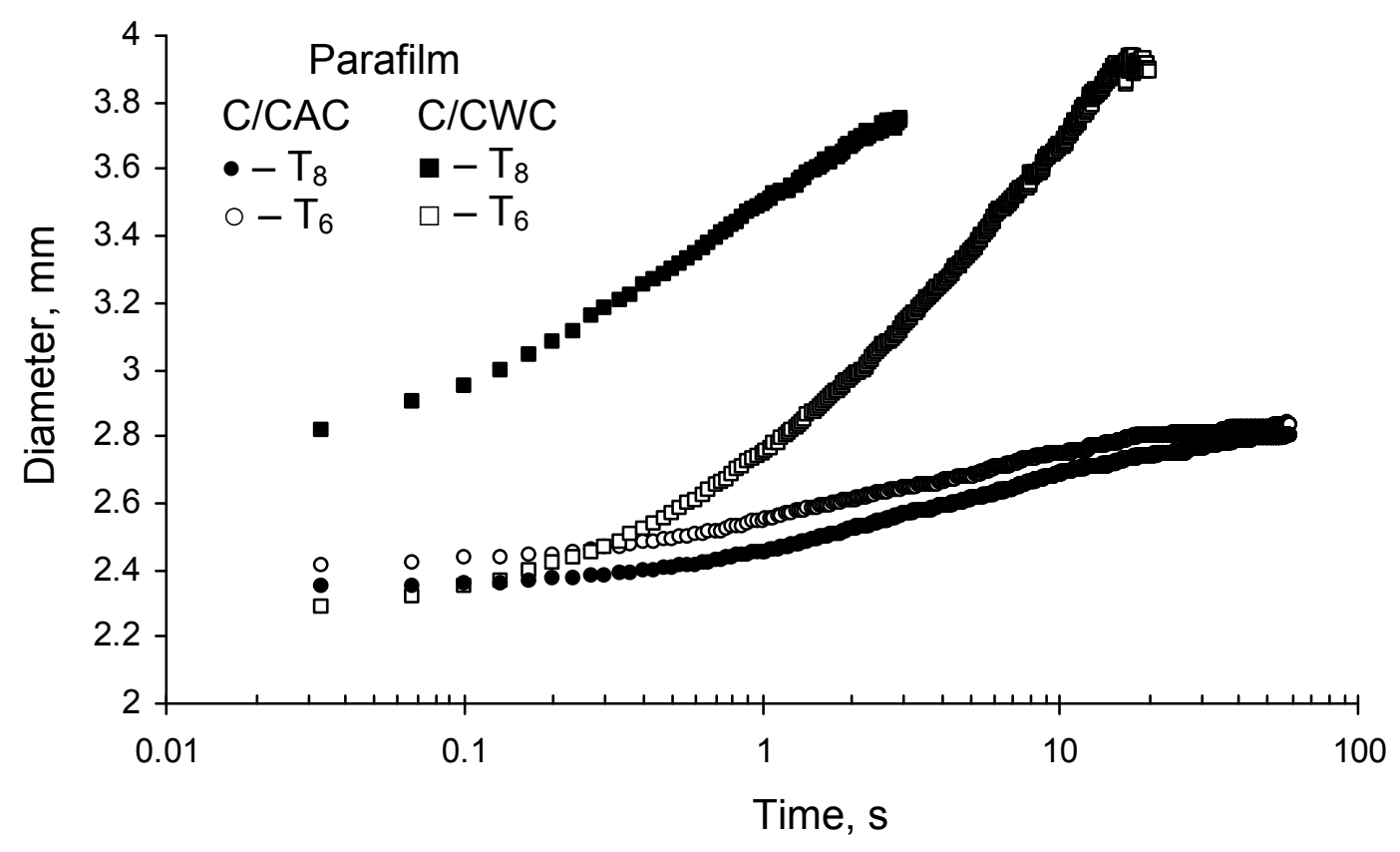

Fig. 2. Spreading kinetic of the droplets of $\mathrm{T}_{6}$ and $\mathrm{T}_{8}$ solutions at concentration $1 \mathrm{CAC}$ and $1 \mathrm{CWC}$ over Parafilm substrate. Concentrations/trisiloxanes: $\bullet-\mathrm{T}_{8}$ solution/1 CAC; $\odot-\mathrm{T}_{6}$ solution/1 CAC; $-\mathrm{T}_{8}$ solution/ $1 \mathrm{CWC} ; \square-\mathrm{T}_{6}$ solution/1 CWC. 


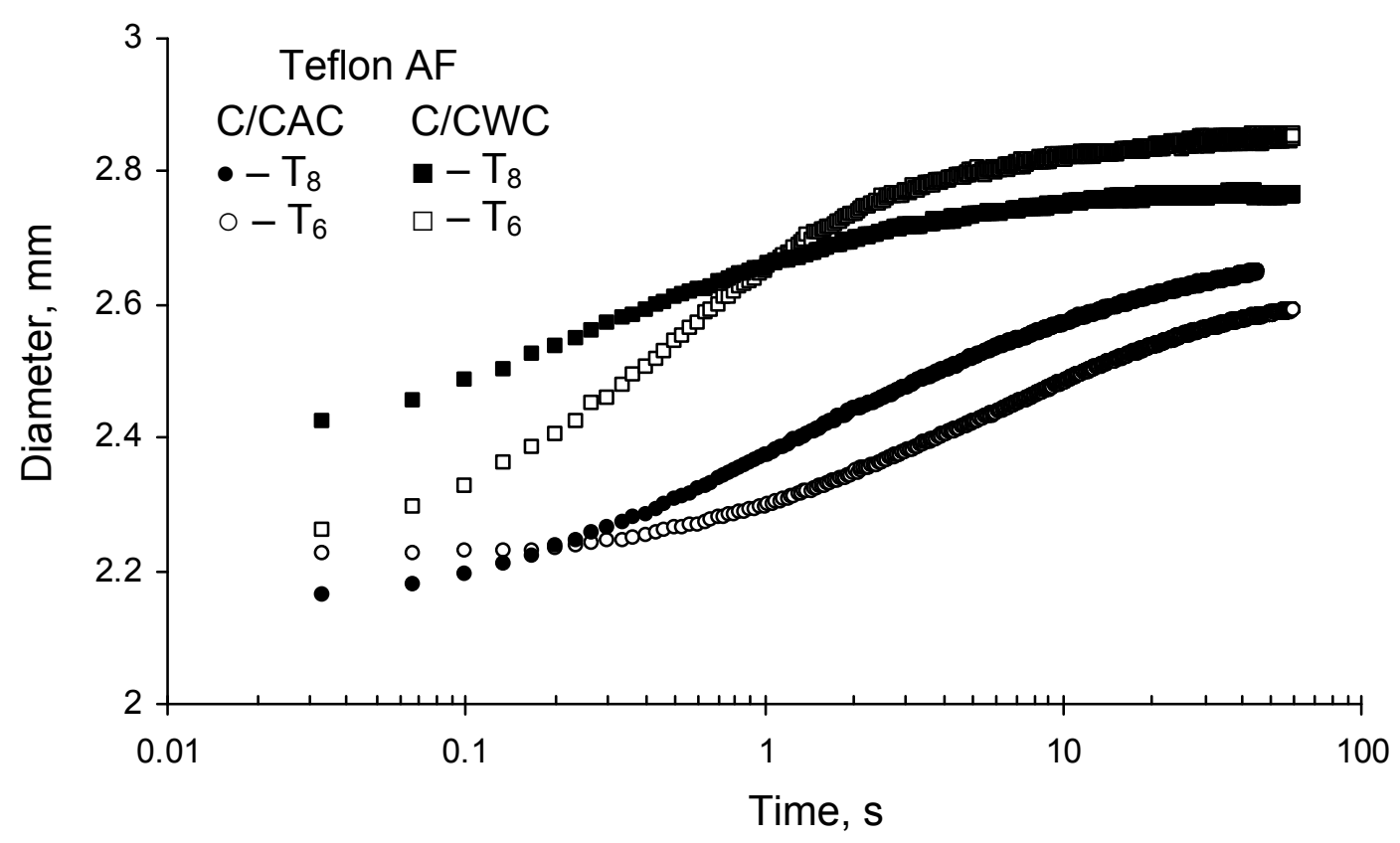

Fig. 3. Spreading kinetic of the droplets of $\mathrm{T}_{6}$ and $\mathrm{T}_{8}$ solutions at concentration near $1 \mathrm{CAC}$ and $1 \mathrm{CWC}$ over Teflon AF substrate. Concentrations/trisiloxanes: $\bullet-\mathrm{T}_{8}$ solution/1 CAC; $\circ-\mathrm{T}_{6}$ solution/1 CAC; $-\mathrm{T}_{8}$ solution/ $1 \mathrm{CWC} ; \square-\mathrm{T}_{6}$ solution/1 CWC. 


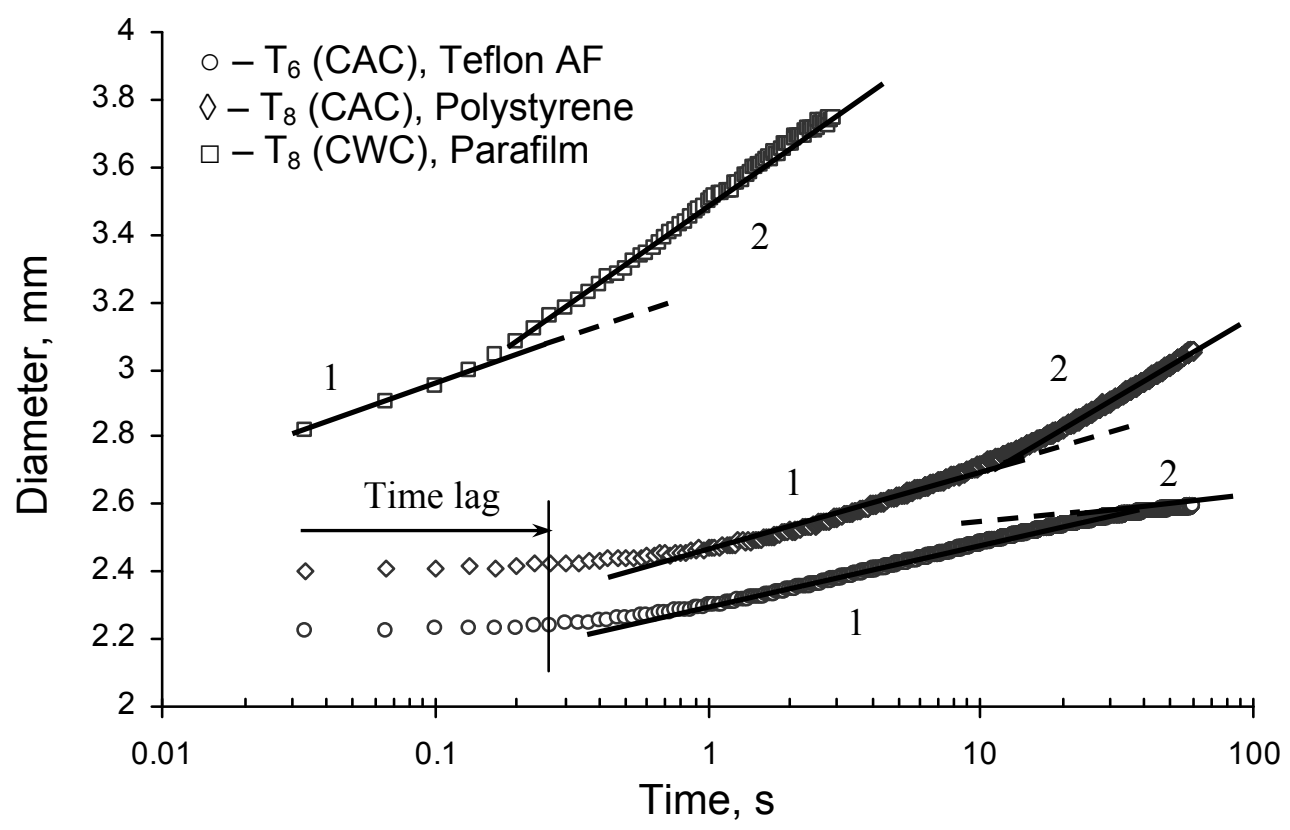

Fig. 4. Dependencies of the droplet diameters on spreading time for $T_{6}$ and $T_{8}$ solutions at different concentrations and polymer substrates: $\bigcirc-\mathrm{T}_{6}(\mathrm{CAC})$, Teflon AF; $\diamond-T_{8}$ (CAC), Polystyrene; $\square-T_{8}$ (CWC), Parafilm. Solid lines fit the first and second stages according to a power law with the corresponding values of exponents shown in Table 3. 


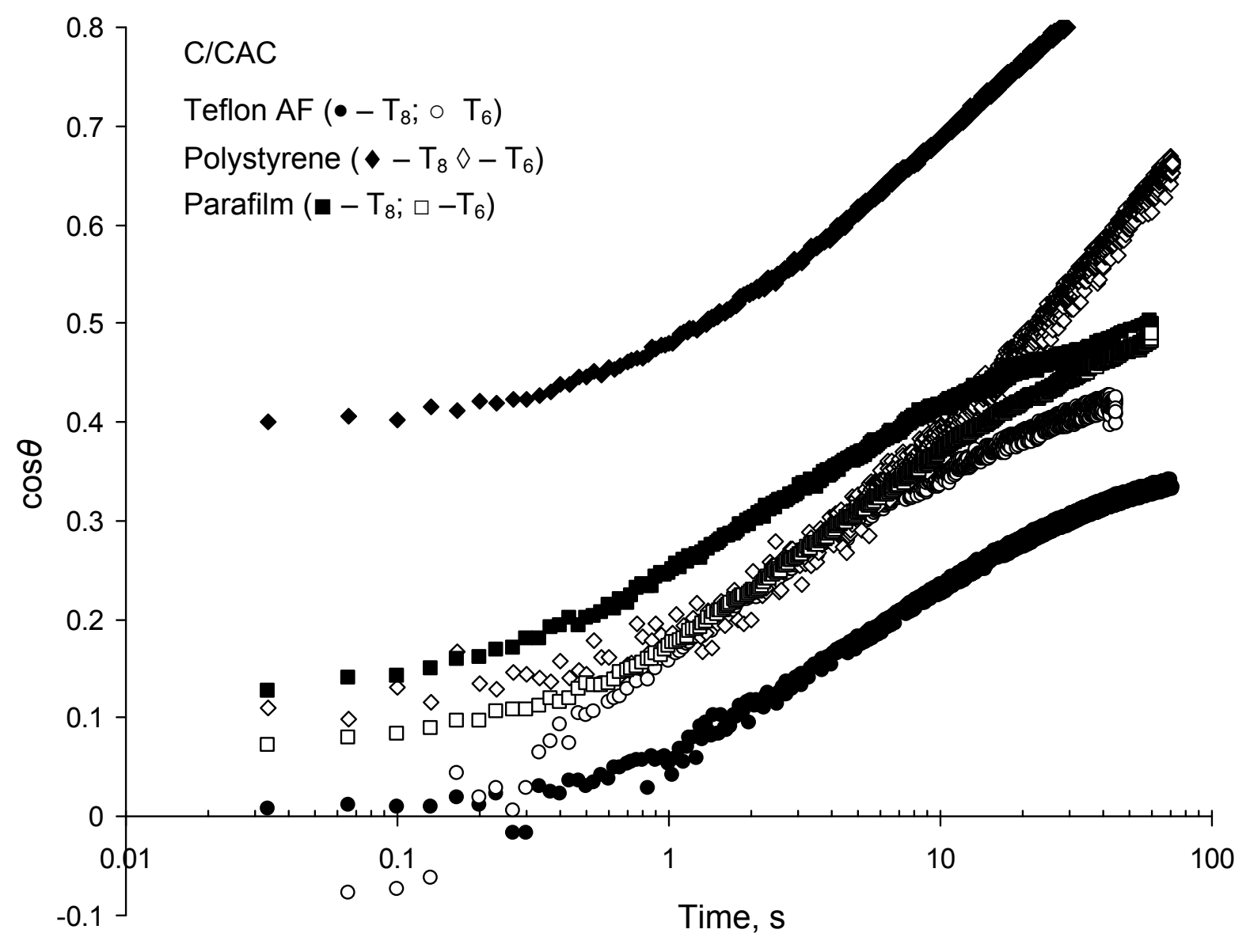

Fig. 5. Time evolution of cosine of the contact angle of droplets $T_{6}$ and $T_{8}$ solutions spreading over different polymer surfaces: •, $\bigcirc-$ Teflon AF; $\mathbf{n}, \square-$ Parafilm; $\diamond, \bullet-$ polystyrene. Concentration of solutions is about 1CAC. 


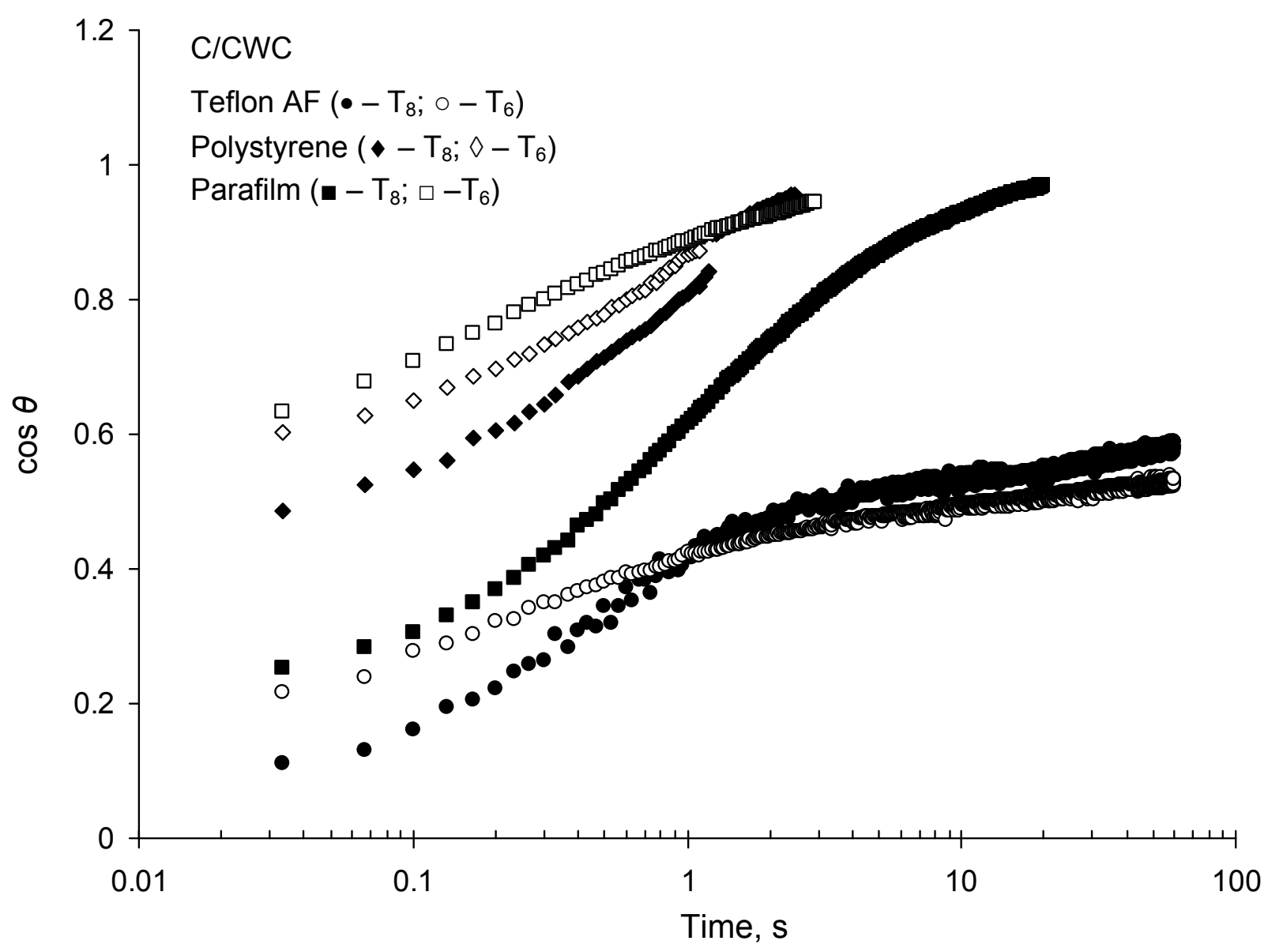

Fig. 6. Time evolution of cosine of the contact angle of droplets $\mathrm{T}_{6}$ and $\mathrm{T}_{8}$ solutions spreading over different polymer surfaces: •, ○-Teflon AF; $\mathbf{-}, \square-$ Parafilm; $\diamond, \bullet-$ polystyrene. Concentration of solutions is about $1 \mathrm{CWC}$. 


\section{Figure legends}

Fig. 1. Spreading kinetic of the droplets of $\mathrm{T}_{6}$ and $\mathrm{T}_{8}$ solutions at concentration $1 \mathrm{CAC}$ and 1 CWC over Polystyrene substrate. Concentrations/trisiloxanes: $\bullet-\mathrm{T}_{8}$ solution/1 CAC; $\circ-\mathrm{T}_{6}$ solution/1 $\mathrm{CAC} ;-\mathrm{T}_{8}$ solution/ $1 \mathrm{CWC} ; \square-\mathrm{T}_{6}$ solution/1 CWC.

Fig. 2. Spreading kinetic of the droplets of $T_{6}$ and $T_{8}$ solutions at concentration $1 \mathrm{CAC}$ and 1 CWC over Parafilm substrate. Concentrations/trisiloxanes: $\bullet-\mathrm{T}_{8}$ solution/1 CAC; $\bigcirc-\mathrm{T}_{6}$ solution/1 CAC; - $-\mathrm{T}_{8}$ solution/ $1 \mathrm{CWC} ; \square-\mathrm{T}_{6}$ solution/1 CWC.

Fig. 3. Spreading kinetic of the droplets of $\mathrm{T}_{6}$ and $\mathrm{T}_{8}$ solutions at concentration $1 \mathrm{CAC}$ and 1 CWC over Teflon AF substrate. Concentrations/trisiloxanes: $\bullet-\mathrm{T}_{8}$ solution/1 CAC; $\circ-\mathrm{T}_{6}$ solution/1 CAC; - $-\mathrm{T}_{8}$ solution/ $1 \mathrm{CWC} ; \square-\mathrm{T}_{6}$ solution/1 CWC.

Fig. 4. Dependencies of the droplet diameters on spreading time for $T_{6}$ and $T_{8}$ solutions at different concentrations and polymer substrates: $\bigcirc-\mathrm{T}_{6}$ (CAC), Teflon AF; $\diamond-\mathrm{T}_{8}$ (CAC), Polystyrene; $\square-\mathrm{T}_{8}(\mathrm{CWC})$, Parafilm. Solid lines fit the first and second stages according to a power law with the corresponding values of exponents shown in Table 3.

Fig. 5. Time evolution of cosine of the contact angle of droplets $\mathrm{T}_{6}$ and $\mathrm{T}_{8}$ solutions spreading over different polymer surfaces: •, $\bigcirc-$ Teflon AF; $\mathbf{-}, \square-$ Parafilm; $\diamond, \bullet-$ polystyrene. Concentration of solutions is about 1CAC.

Fig. 6. Time evolution of cosine of the contact angle of droplets $T_{6}$ and $T_{8}$ solutions spreading over different polymer surfaces: $\bullet, \bigcirc-$ Teflon AF; $\mathbf{-}, \square-$ Parafilm; $\diamond,-$ - polystyrene. Concentration of solutions is about $1 \mathrm{CWC}$. 